\title{
CULTIVO CONSORCIADO DE AVEIA E ERVILHACA: RELAÇÃO C/N DA FITOMASSA E PRODUTIVIDADE DO MILHO EM SUCESSÃO(1)
}

\author{
R. HEINRICHS (2), C. AITA(3), T.J . C. AMADO(3) \& A. L. FANCELLI(4)
}

\begin{abstract}
RESUMO
A aveia e a ervilhaca são as principais culturas de cobertura de solo utilizadas durante o inverno na região sul do Brasil. $\mathbf{O}$ cultivo consorciado dessas duas espécies, estratégia ai nda pouco utilizada, pode potencialmente resultar numa fitomassa com relação $\mathrm{C} / \mathrm{N}$ mais equilibrada do que aquela proveniente das culturas solteiras, bem como proporcionar resíduos culturais que atuem, simultaneamente, na proteção do solo contra os agentes erosi vos e no suprimento de $\mathbf{N}$ ao mi lho. Com o objetivo de avaliar esta hipótese, realizou-se este trabalho, durante o ano agrícola de 1992/93, em área do Departamento de Solos da Universidade Federal de Santa Maria, num Argi ssolo Vermel ho distrófico arênico (Hapludalf). Os tratamentos constaram de diferentes proporções de densidade de semeadura de ervilhaca comum (E) e aveia preta (A): T1: 100\%E (80 kg ha-1de sementes); T2: 90\%E (72 kg ha-1) + 10\%A (8 kg ha-1); T3: 75\%E (60 kg ha-1) + 25\%A (20 kg ha-1); T4: 50\%E (40 kg ha-1) +50\%A (40 kg ha-1); T5: 25\%E (20 kg ha-1) + 75\% A (60 kg ha-1) e T6: $100 \%$ A (80 kg ha-1). Além desses, foram utilizados dois tratamentos, nos quais o solo permaneceu em pousio durante o inverno: no primeiro tratamento, foram aplicados $75 \mathrm{~kg} \mathrm{ha}^{-1}$ de $\mathrm{N}$-uréia no milho (T7) e, no segundo, a cultura foi plantada sem adubação nitrogenada (T8). Em sucessão à ervilhaca como cultura solteira, com relação $\mathrm{C} / \mathrm{N}$ de 13,5 , a produtividade de grãos de milho chegou a 5,44 $\mathrm{tha}^{-1}$, não diferindo do tratamento em pousio com aplicação de $\mathbf{N}$-uréia. Todavia, a ervilhaca foi rapidamente decomposta e, seis meses após o seu manejo, apenas $19,5 \%$ da fitomassa inicial encontrava-se na superfície do solo. Com a inclusão da aveia em consórcio com a ervil haca ocorreu um aumento gradativo na relação $\mathrm{C} / \mathrm{N}$ da fitomassa, di minuindo o fornecimento de $\mathbf{N}$ ao milho e aumentando a persistência dos resíduos culturais. $\mathbf{O}$ consórcio que apresentou mel hor equilíbrio entre produção de fitomassa, proteção do solo pelos resíduos culturais e fornecimento de $\mathbf{N}$ ao mil ho foi o que continha $10 \%$ de aveia $+90 \%$ de ervilhaca (relação $\mathrm{C} / \mathrm{N}=18,6$ ).
\end{abstract}

Termos de indexação: plantas de cobertura, nitrogênio, plantio direto, Vicia sativa L., Avena strigosa Schieb., Zea mays L.

\footnotetext{
(1) Parte da Tese de Mestrado do primeiro autor, apresentada à Escola Superior de Agricultura "Luiz de Queiroz", Universidade de São Paulo. Recebido para publicação em agosto de 2000 e aprovado em janeiro de 2001.

(2) Doutorando no laboratório de Nutrição Mineral de Plantas, Centro de Energia Nuclear na Agricultura / Universidade de São Paulo - USP. Caixa Postal 96, CEP 13400-970 Piracicaba (SP). Bolsista FAPESP.

(3) Professor do Departamento de Solos da Universidade Federal de Santa Maria - UFSM. CEP 97105-900 Santa Maria (RS). Bolsista do CNPq.

(4) Professor do Departamento de Produção Vegetal da Escola Superior de Agricultura “Luiz de Queiroz", Universidade de São Paulo - USP. Caixa Postal 9, CEP 13418-900, Piracicaba (SP).
} 


\title{
SUMMARY: VETCH-OATS MIXTURES: BIOMASS C/ N RATIO AND CORN PRODUCTION
}

\begin{abstract}
Black oats and common vetch are the main winter cover crops in southern Brazil. Grass-l egume bicul tures grown as winter cover crops are rarely used by farmers, although they can provide a more balanced bi omass $\mathrm{C} / \mathrm{N}$ ratio than single crops, besides erosion control and $\mathrm{N}$ supply to corn. In order to eval uatethis hypothesis, this work was carried out on a Hapludalf with a sandy-loam texture, located at the Federal University of Santa Maria (RS). The treatments comprised different seeding density rates of common vetch (V) and black oats (O): T1: $100 \% \mathrm{~V}\left(80 \mathrm{~kg} \mathrm{ha}^{-1}\right) ; \mathrm{T} 2: 90 \% \mathrm{~V}\left(72 \mathrm{~kg} \mathrm{ha}^{-1}\right)+10 \% \mathrm{O}\left(8 \mathrm{~kg} \mathrm{ha}^{-1}\right) ; \mathrm{T} 3: 75 \% \mathrm{~V}$ $\left(60 \mathrm{~kg} \mathrm{ha}^{-1}\right)+25 \% \mathrm{O}\left(20 \mathrm{~kg} \mathrm{ha}^{-1}\right) ; \mathrm{T} 4: 50 \% \mathrm{~V}\left(40 \mathrm{~kg} \mathrm{ha}^{-1}\right)+50 \%$ O (40 kg ha-1); T5: $25 \% \mathrm{~V}$ $\left(20 \mathrm{~kg} \mathrm{ha}^{-1}\right)+75 \% \mathrm{O}\left(60 \mathrm{~kg} \mathrm{ha}^{-1}\right)$ and T6: 100\%O $\left(80 \mathrm{~kg} \mathrm{ha}^{-1}\right)$. Two moretreatments including winter fallow werealso used: T7 was cultivated with corn with $75 \mathrm{~kg} \mathrm{ha}^{-1}$ of N-urea and T8 was cultivated with corn without $\mathrm{N}$ fertilizer. I n succession to vetch as a singlecrop, with a $\mathrm{C} / \mathrm{N}$ ratio of 13.5 , corn grain yield was $5.44 \mathrm{Mg} \mathrm{ha}^{-1}$, which did not differ from the fallow treatment with $\mathrm{N}$-urea application. However, vetch residuewas rapidly decomposed, so that only $19.5 \%$ of the original biomass remained on the soil surface 6 months after its management. By including oat in the mixturewith vetch, gradual increasein biomass $\mathrm{C} / \mathrm{N}$ ratio was observed, reducing the $\mathrm{N}$ supply to corn and increasing residue persistence. The mixturewhich best comprised biomass production, soil cover by cover crops residues and $\mathrm{N}$ supply to corn was that consisting of $10 \%$ of oat plus $90 \%$ of vetch (C/ $\mathrm{N}$ ratio of 18.6 ).
\end{abstract}

Index terms: cover crops, nitrogen, no-tillage, Vicia sativa L., Avena strigosa Schieb., Zea mays $L$.

\section{NTRODUÇÃO}

A utilização de plantas de cobertura durante o período de entressafra proporciona a melhoria da capacidade produtiva do solo, favorece sua estruturação e fornece nutrientes às culturas em sucessão (Wildner \& Dadalto, 1992), além de promover a manutenção ou até mesmo incremento dos teores de matéria orgânica e de contribuir para o controle de plantas invasoras pel o efeito supressor/ al el opático (Calegari et al., 1993). Acentuada redução nas perdas de solo e de água e a diminuição da temperatura do solo durante o verão, decorrentes da presença de resíduos culturais na superfície, após o manejo das espécies de inverno, têm sido relatadas em inúmeros trabal hos de pesquisa (Derpsch et al., 1985; Bragagnolo \& Mielniczuk, 1990; Debarba \& Amado, 1997).

Nos últimos anos, com a diminuição da área de cultivo de trigo na região sul do Brasil, tem aumentado o interesse por parte dos produtores pelas culturas de outono/inverno para cobertura de solo, destacando-se a aveia preta (Avena strigosa Schieb.), dentre as gramíneas, ea ervilhaca comum (Vicia sativa L.), dentre as leguminosas.

A aveia caracteriza-se pela el evada capacidade de produção de fitomassa, além de apresentar resistência satisfatória à ferrugem, ao ataque de pulgões eà deficiência hídrica. Ela tem sido incluída em sistemas de rotação de culturas visando à eliminação de patógenos, com ótimos resultados sobre a produtividade da culturas da soja e do feijão (Derpsch \& Calegari, 1985). Por outro lado, se a cultura em sucessão à aveia for o milho, a produtividade de grãos desta cultura pode ser afetada especialmente na ausência ou em baixos níveis de adubação nitrogenada e em solos pobres em matéria orgânica (Aita et al., 1994; Pavinato et al., 1994).

Quanto à ervilhaca, a preferência pela espécie deve-se principal mente à sua capacidade de fixar o $\mathrm{N}_{2}$ atmosférico, fato que contribui para a melhoria do balanço de $\mathrm{N}$ no solo. Os trabalhos de pesquisa realizados com esta espécie evidenciam que, além de propiciar a cobertura do solo, protegendo-o da erosão, ela fornece $\mathrm{N}$ ao milho em sucessão, podendo substituir parcial (Aita et al., 1994) ou totalmente (Da Ros \& Aita, 1996) a adubação mineral nitrogenada da cultura. Apesar destes benefícios, nota-se que os resídu os culturais da ervil haca, como cultura solteira, desaparecem rapidamente, mesmo quando deixados na superfície do solo, dada a facilidade com que são decompostos pela população microbiana, contrariamente àqueles da aveia que persistem por mais tempo (Da Ros \& Aita, 1996).

O principal fator inerente às culturas de cobertura de solo que condiciona a velocidade de decomposi ção e de li beração de nutrientes dos seus 
resíduos culturais é a relação $\mathrm{C} / \mathrm{N}$, que é menor na ervilhaca do que na aveia. Para Siqueira \& Franco (1988), quando a relação C/N situa-se entre 20 e 30, ocorre um equilíbrio entre os processos de mineralização e de imobilização do nitrogênio; quando atinge valores superiores a 30, a imobilização supera a mineralização. Todavia, para Derpsch et al. (1985), com uma relação C/N superior a 25 já é possível ocorrer imobilização líquida de $\mathrm{N}$.

Com base no exposto, admite-se que o cultivo consorciado de aveia e ervilhaca proporcione uma fitomassa que se decomponha mais lentamente no solo do que a ervilhaca solteira, protegendo-o dos agentes erosivos e, ao mesmo tempo, forneça mais $\mathrm{N}$ ao milho em sucessão do que a aveia solteira. Para que a proteção do sol o e o suprimento de $\mathrm{N}$ ao milho sejam maximizados, é necessário conhecer a dinâmica de decomposição e de liberação de $\mathrm{N}$ dos resíduos culturais oriundos da aveia e ervilhaca, quando consorciadas em diferentes proporções de densidade de semeadura. Este é um assunto ainda muito pouco estudado no Brasil.

O objetivo deste trabalho foi o de avaliar a performance da aveia e da ervilhaca, como culturas solteiras e consorciadas em diferentes proporções, bem como sua influência na relação $\mathrm{C} / \mathrm{N}$ da fitomassa, na persistência dos resíduos culturais após o manejo das espécies, no fornecimento de $\mathrm{N}$ e na produtividade de grãos de milho em sucessão.

\section{MATE RIAL E MÉTODOS}

O trabal hofoi realizado na área experimental do Departamento de Sol os da U niversidade F ederal de Santa Maria (UFSM), durante o ano agrícola 1992/ 93, em um Argissolo Vermelho distrófico arênico relevo ondulado, com as seguintes características químicas na camada 0-20 cm: $\mathrm{pH}$ H2O (1:1): 5,3; M.O.: $17 \mathrm{~g} \mathrm{dm}^{-3} ; \mathrm{P}: \quad 7,9 \mathrm{mg} \mathrm{dm}^{-3}$ (Mehlich-1); K: $2,2 \mathrm{mmol}_{\mathrm{c}} \mathrm{dm}^{-3} ; \mathrm{Al}: 4 \mathrm{mmol}_{\mathrm{c}} \mathrm{dm}^{-3} ; \mathrm{Ca}+\mathrm{Mg}$ : $42 \mathrm{mmol}_{\mathrm{c}} \mathrm{dm}^{-3}$.

O clima da regiãoé subtropical úmido, tipo Cfa2, conforme classificação deKöppen. As médias anuais de temperatura, precipitação pluviométrica e umidade relativa do ar são de, respectivamente, 19,3ㄷ, 1.561 mm e 82\%. Maio, junho e outubro são considerados os meses mais chuvosos e novembro, dezembro e março os menos chuvosos; julho é considerado o mês mais frio, com valor médio das temperaturas mínimas de 9,3C, e janeiro o mês mais quente, com média das temperaturas máximas de $31,8{ }^{\circ} \mathrm{C}$.

O delineamento experimental foi o de blocos ao acaso, com quatro repetições, em parcelas de $5 \times 4 \mathrm{~m}$. Os tratamentos consistiram de proporções de densidade de semeadura de ervilhaca comum (Vicia sativa L.) (E) eaveia preta (Avena strigosa Schieb.) (A).
As proporções utilizadas foram as seguintes: T1: 100\% E (80 kg ha-1 de sementes); T2: $90 \% \mathrm{E}\left(72 \mathrm{~kg} \mathrm{ha}^{-1}\right)+$ 10\% A (8 kg ha-1); T3: 75\% E (60 kg ha-1) $+25 \%$ A (20 kg ha-1); T4: $50 \% \mathrm{E}\left(40 \mathrm{~kg} \mathrm{ha}^{-1}\right)+50 \% \mathrm{~A}\left(40 \mathrm{~kg} \mathrm{ha}^{-1}\right)$; T5: $25 \% \mathrm{E}\left(20 \mathrm{~kg} \mathrm{ha}^{-1}\right)+75 \% \mathrm{~A}\left(60 \mathrm{~kg} \mathrm{ha}^{-1}\right)$ e T6: $100 \%$ A (80 kg ha-1). Além desses, foram utilizados dois tratamentos em pousio invernal, tendo sido aplicados $75 \mathrm{~kg} \mathrm{ha}^{-1}$ de N-uréia no milho (T7) e, no outro, o milho foi cultivado sem a aplicação de $\mathrm{N}$ (T8).

Para o plantio da aveia e da ervilhaca, o solo foi preparado pelo sistema convencional, com uma aração e uma gradagem. A semeadura de ambas as culturas foi feita manualmente a lanço, em 19/05/ 1992, sem adubação, e as sementes da ervilhaca inoculadas com a estirpe de Rhizobi um SEMIA 384. Utilizaram-se 10 g de inoculanteà base deturfa para cada kg de sementes.

$\mathrm{Na}$ época do pleno florescimento das culturas de cobertura de solo, 130 dias após a semeadura, coletou-se a parte aérea, em uma área de 0,80 $\mathrm{m}^{2}$ por parcela, para avaliar a produção de matéria seca e os teores de $\mathrm{N}$ total e $\mathrm{C}$ orgânico. A matéria seca foi determinada após secagem do material em estufa a $65{ }^{\circ} \mathrm{C}$ até massa constante. A concentração de $\mathrm{N}$ total foi avaliada digerindo-se $0,200 \mathrm{~g}$ de tecido vegetal seco e moído, na presença deácido sulfúrico, peróxido de hidrogênio e mistura de digestão $\left(\mathrm{K}_{2} \mathrm{SO}_{4}+\mathrm{CuSO}_{4} \cdot 5 \mathrm{H}_{2} \mathrm{O}\right)$, e posterior destilação em destilador de arraste de vapor semimicro Kjeldhal (Tedesco et al., 1985). O carbono orgânico foi determinado pelo método de Walkley \& Black , descrito por Tedesco et al. (1985), analisando-se apenas uma amostra de tecido vegetal em cada tratamento. Essa amostra composta foi constituída a partir das quatro repetições de cada tratamento, obedecendo-se à proporção na produção de fitomassa de cada uma das repetições.

Logo após a amostragem, as plantas de cobertura foram manejadas com grade niveladora, regulada de forma a provocar o acamamento e interrupção no ciclo vegetativo das espécies, com o mínimo revolvimento do solo. Seis meses após o manejo, foram amostrados os resíduos culturais remanescentes na superfície do solo numa área de $0,25 \mathrm{~m}^{2}$ por parcela, exceto nos dois tratamentos em pousio, em que a vegetação espontânea não foi coletada. Nos resíduos culturais, secos e moídos, analisaram-se os teores de $\mathrm{N}$ total, seguindo-se o mesmo método anteriormente descrito (Tedesco et al., 1985).

Para o milho híbrido Cargill 511-A, adotou-se o sistema plantio direto, sete dias após o acamamento das plantas de cobertura, utilizando-se o espaçamento de 0,90 m entrelinhas e uma população de 50.000 plantas ha-1. Na semeadura, o milho foi adubado em todos os tratamentos, conforme a recomendação para a cultura (Siqueira et al., 1987), aplicando-se $50 \mathrm{~kg} \mathrm{ha}^{-1} \mathrm{de}_{2} \mathrm{O}_{5}$ e $75 \mathrm{~kg} \mathrm{ha}^{-1}$ de $_{2} \mathrm{O}$, 
na forma de superfosfato triplo e cl oreto de potássio, respectivamente. Apenas no tratamento com adubação mineral nitrogenada (T7), foram aplicados $75 \mathrm{~kg} \mathrm{ha}^{-1}$ de N no milho, na forma de uréia, sendo $15 \mathrm{~kg} \mathrm{ha}^{-1}$ na semeadura e o restante em cobertura, noestádio deoitofol has. A aplicação deN em cobertura foi feita na superfície do sol oaolado da linha de semeadura do milho, em condi ções favoráveis de umidade.

Noestádio de plenoflorescimento do mil ho, foram col etadas al eatoriamente cinco plantas, na área útil de cada parcela, para avaliar a produção de matéria seca e a concentração de $\mathrm{N}$ total, utilizando os mesmos procedimentos analíticos descritos anteriormente para as plantas de cobertura. A produtividade final de grãos foi avaliada, coletandose uma área útil de $15,75 \mathrm{~m}^{2}$ por parcela, corrigindose os valores de umidade para $13 \%$.

A partir das quantidades de $\mathrm{N}$ acumulado na parte aérea do milho $\left(\mathrm{kg} \mathrm{ha}^{-1} \mathrm{de} \mathrm{N}\right)$ nos tratamentos com ervilhaca como cultura solteira (T1), pousio + N (T 7) e pousio sem aplicação de N (T8), estimou-se a eficiência aparente do $\mathrm{N}$ aplicado com a leguminosa e com a uréia. Para isso, utilizou-se a equação proposta por Mitchell \& Teel (1977):

em que:

$$
E_{f} \text { aN }=\frac{N T-N P}{N a p} \times 100
$$

$\mathrm{E}_{\mathrm{f}} \mathrm{aN}=$ eficiência aparente do $\mathrm{N}$ aplicado;

NT = quantidade de $\mathrm{N}$ acumulado pel o milho nos tratamentos com ervilhaca como cultura sol teira ou apenas solteira ou pousio $+\mathrm{N}$;

$\mathrm{NP}=$ quantidade de $\mathrm{N}$ acumulado pel o milho no tratamento em pousio sem aplicação de $\mathrm{N}$;

Nap = quantidade de $\mathrm{N}$ aplicado via fertilizante ou leguminosa.
A análise estatística dos resultados constou das análises de variância, comparando-se as médias pelo teste de Tukey a $5 \%$, e de correl ação, testando-se os coeficientes pelo teste t de Student.

\section{RESULTADOS E DISCUSSÃO}

\section{Produção de matéria seca (MS) e relação $\mathrm{C} / \mathrm{N}$ das plantas de cobertura}

Pelos resultados (Quadro 1), observa-se que, na época do manejo das plantas de cobertura, a produção de MS total da parte aérea não diferiu significativamente entre os tratamentos que continham aveia preta na sua composição. A grande capacidade competitiva desta gramínea, quando consorciada à ervil haca, fica evidente no tratamento T2, em que a aveia, com apenas $10 \%$ na densidade de semeadura, contribuiu com mais da metade (52,2\%) da produção total de MS do consórcio. Tais resultados confirmam os obtidos por Ouknider et al. (1991) e corroboram a afirmação de M onegat (1991) de que a aveia é uma planta com maior rusticidadee agressividade do que a ervilhaca, além de apresentar como característica a capacidade de perfilhar .

Analisandoa produção deMS deervil haca eaveia, observa-se que esta esteve diretamente relacionada com a proporção que ambas ocuparam nos diferentes tratamentos (Quadro 1). A produção da ervilhaca foi maior no tratamento que continha a espécie como cultura solteira $\left(2,73 \mathrm{t} \mathrm{ha}^{-1}\right)$ e na proporção de $90 \%$ $\left(1,87\right.$ t ha-1 $\left.^{-1}\right)$, diminuindo sensivelmenteà medida que aumentou a participação da aveia no consórcio, chegando a apenas 0,58 t ha-1 notratamento T5 (25\% $E+75 \%$ A). Esta tendência evidencia a baixa capacidade de competição da leguminosa.

Quadro 1. Produção de matéria seca (MS), relação C/N das culturas de cobertura do solo no momento do manejo e quantidade de resíduos culturais aos 180 dias do manejo

\begin{tabular}{|c|c|c|c|c|c|c|c|}
\hline \multirow{3}{*}{ Tratamento } & \multicolumn{5}{|c|}{$\mathrm{Na}$ época do manejo } & \multirow{2}{*}{\multicolumn{2}{|c|}{$\begin{array}{c}180 \text { dias após o manejo } \\
\text { Matéria seca }\end{array}$}} \\
\hline & \multicolumn{4}{|c|}{ Matéria seca } & \multirow[b]{2}{*}{ Relação C/N (2) } & & \\
\hline & Ervilhaca & Aveia & Total & $\begin{array}{l}\text { Contribuição } \\
\text { da aveia }\end{array}$ & & Total & Redução na MS \\
\hline & + & $-\mathrm{t} \mathrm{ha}^{-1}$ & - & $\%$ & & $\mathrm{t} \mathrm{ha}^{-1}$ & $\%$ \\
\hline 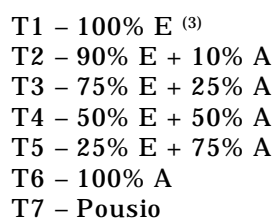 & $\begin{array}{l}2,73 \mathrm{a}^{(1)} \\
1,87 \mathrm{ab} \\
1,56 \mathrm{~b} \\
1,00 \mathrm{bc} \\
0,58 \mathrm{c} \\
- \\
-\end{array}$ & $\begin{array}{l}- \\
2,30 \mathrm{~b} \\
2,88 \mathrm{~b} \\
3,71 \mathrm{ab} \\
4,60 \mathrm{a} \\
4,91 \mathrm{a} \\
-\end{array}$ & $\begin{array}{l}2,73 \mathrm{bc} \\
4,17 \mathrm{ab} \\
4,44 \mathrm{ab} \\
4,71 \mathrm{a} \\
5,19 \mathrm{a} \\
4,91 \mathrm{a} \\
1,43 \mathrm{c}\end{array}$ & $\begin{array}{c}0 \\
52,2 \\
65,5 \\
78,8 \\
88,8 \\
100,0 \\
-\end{array}$ & $\begin{array}{l}13,5 \\
18,6 \\
19,6 \\
24,0 \\
27,2 \\
33,9 \\
16,5\end{array}$ & $\begin{array}{l}0,53 \mathrm{~d} \\
1,53 \mathrm{c} \\
1,81 \mathrm{bc} \\
1,77 \mathrm{bc} \\
2,31 \mathrm{ab} \\
2,63 \mathrm{a} \\
-\end{array}$ & $\begin{array}{c}80,5 \\
63,3 \\
59,2 \\
62,4 \\
55,5 \\
46,4 \\
-\end{array}$ \\
\hline C.V. (\%) & 21,5 & 18,6 & - & - & - & - & - \\
\hline
\end{tabular}

(1) Médias seguidas das mesmas letras não diferem entre si (Tukey a 5\%). ${ }^{(2)}$ Relação $\mathrm{C} / \mathrm{N}$ da matéria seca total. ${ }^{(3)} \mathrm{E}=e$ rvilhaca; $\mathrm{A}=$ aveia. 
Nas parcelas com aveia, também houve decréscimo na produção de MS da espécie com a diminuição de sua proporção no consórcio. Todavia, a produção de MS não diferiu significativamente entre os tratamentos com aveia solteira $\left(4,91 \mathrm{t} \mathrm{ha}^{-1}\right)$ e com $50 \%$ de aveia $+50 \%$ de ervilhaca $\left(3,71 \mathrm{t} \mathrm{ha}^{-1}\right)$. O tratamentoT2 $(90 \% \mathrm{E}+10 \% \mathrm{~A})$ apresentou maior equilíbrio na produção das duas espécies $(52,2 \%$ de fitomassa de aveia e $47,8 \%$ de ervilhaca), ratificando os resultados obtidos por Caballero et al. (1995).

A relação $\mathrm{C} / \mathrm{N}$ das plantas de cobertura atingiu o valor máximo de 33,9 com a semeadura exclusiva da aveia (T6) e mínimo de 13,5 na ervilhaca como cultura solteira (T1). Nos consórcios, a relação C/N variou de acordo com a espécie predominante, variando de 18,6 com $10 \%$ de aveia a 27,2 , quando a proporção desta gramínea aumentou para $90 \%$ (Quadro 1). Este aumento na relação C/N provocado pela presença da aveia no consórcio com a leguminosa é semel hante ao relatado por Monegat (1991) e por Mitchell \& Teel (1977). A relação C/N do tratamento 77 refere-se à vegetação espontânea da área experimental e apresenta valores intermediários aos observados nos tratamentos com consórcio de aveia e ervilhaca (Quadro 1).

\section{Nitrogênio acumulado na fitomassa das culturas de cobertura}

A quantidade de nitrogênio acumulado na parte aérea das plantas, quando consorciadas em diferentes proporções, bem como a contribuição isolada de cada espécie, é apresentada na figura 1. Observa-se que pequeno aumento na proporção de aveia na consorciação provocou acentuado decréscimo na quantidade de $\mathrm{N}$ acumulado pela ervilhaca, em razão da menor produção desta leguminosa. Com apenas $10 \%$ de aveia (T2), o N acumulado pela ervilhaca já passou a ser significativamente inferior (Tukey a 5\%) ao do tratamento com a leguminosa como cultura sol teira (74,8 kg ha-1 de N). Quanto à aveia, esta se mostrou menos sensível ao aumento da ervilhaca no consórcio. Mesmo com apenas 25\% deaveia (T3) o N acumulado pela aveia $\left(41,4 \mathrm{~kg} \mathrm{ha}^{-1} \mathrm{deN}\right)$ não diferiu significativamente do tratamento com a gramínea como cultura solteira $\left(56,2 \mathrm{~kg} \mathrm{ha}^{-1} \mathrm{de} \mathrm{N}\right)$.

Esses resultados evidenciam a grande capacidade da aveia em competir pelo $\mathrm{N}$ mineral do solo, proveniente da mineralização da matéria orgânica. Outro aspecto que pode explicar a boa performance da aveia, mesmo quando presente numa baixa proporção de densidade de semeadura em relação à ervilhaca, seria a transferência de $\mathrm{N}$ da leguminosa à gramínea, quando estas são consorciadas, conforme observaram McNeil \& Wood (1990) e Elgersma \& Hassink (1997) no consórcio de trevo-branco com azevém. Goodman (1988) também consorciou estas duas espécies e verificou quea contribuição do trevo no fornecimento de $\mathrm{N}$ ao azevém se deu principalmente via decomposição de fol has vel has e raízes.

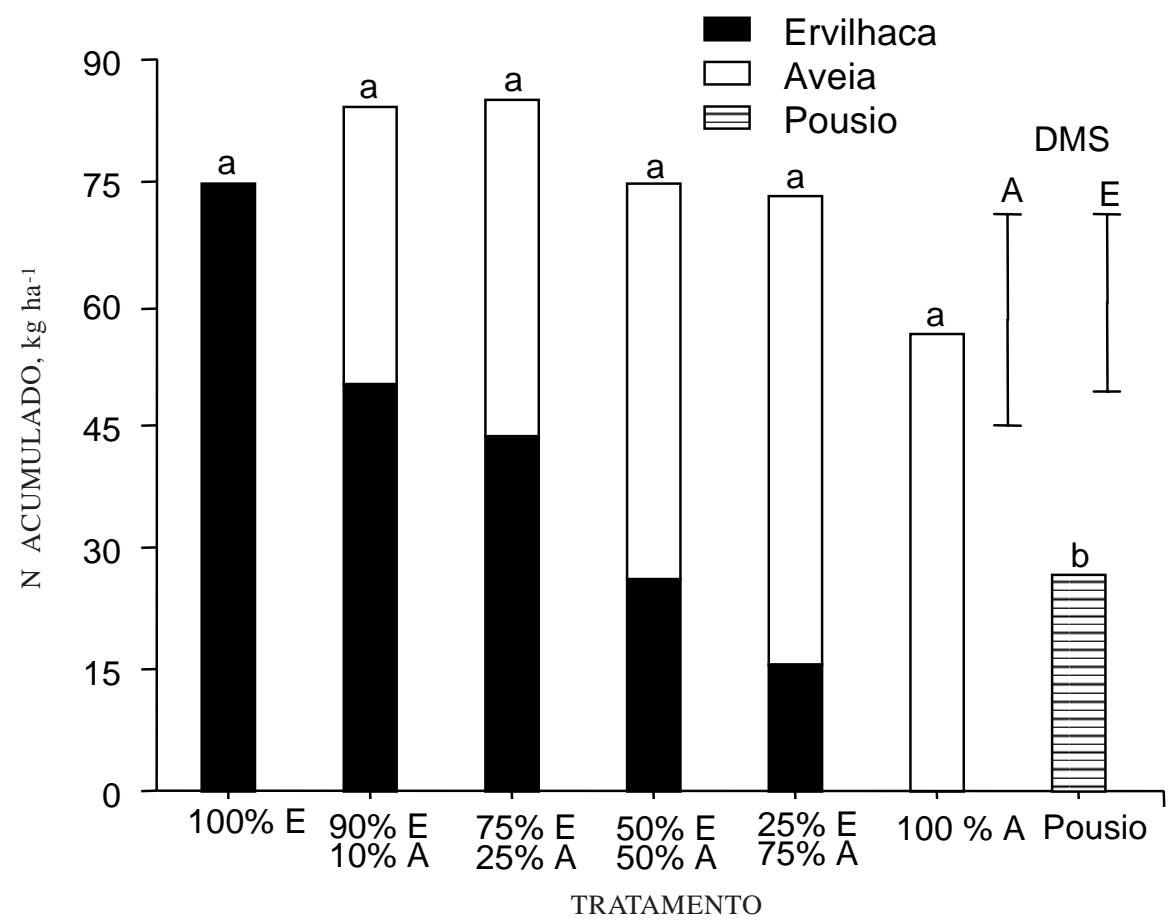

Figura 1. Nitrogênio acumulado pela parte aérea da ervilhaca (E) e aveia (A), na época da floração e vegetação espontânea (pousio). As médias para as quantidades totais de $\mathbf{N}$ acumulado, seguidas das mesmas letras, não diferem entre si (Tukey a 5\%). 
Quanto ao acúmulo total de $\mathrm{N}$ nos diversos tratamentos, observa-se que este chegou a $85 \mathrm{~kg} \mathrm{ha}^{-1}$ de $\mathrm{N}$ no tratamento que continha $75 \%$ de ervilhaca e $25 \%$ de aveia (T3) (Figura 1). Todavia, este valor não diferiu significativamente dos demais tratamentos, os quais superaram apenas o pousio (T7), onde a vegetação espontânea acumulou somente $26,6 \mathrm{~kg} \mathrm{ha}^{-1}$ de $\mathrm{N}$. Como a vegetação espontânea (T7) da área experimental não continha a presença de leguminosas, pode-se considerar que o $\mathrm{N}$ acumulado na fitomassa desse tratamento foi proveniente exclusivamente da mineralização do N orgânico do solo. O fato de a aveia como cultura solteira ter acumulado $29,6 \mathrm{~kg} \mathrm{ha}^{-1}$ de $\mathrm{N}$ a mais do que a vegetação espontânea pode ser atribuído à eficiência da espécie em extrair $\mathrm{N}$ mineral do solo, embora a possibilidade da ocorrência de bactérias associadas à rizosfera da aveia não possa ser descartada. Embora não determinada no presente estudo, a contribuição de bactérias, especialmente do gênero Azospirillum, no aumento do acúmulo de $\mathrm{N}$ em gramíneas como trigo, sorgo e milho tem sido evidenciada em alguns trabalhos (Baldani et al., 1987; Boddey \& Döbereiner, 1988).

\section{Persistência dos resíduos culturais das culturas de cobertura}

$\mathrm{Na}$ figura 2, é mostrada a relação entre a quantidade de resíduos culturais remanescentes 180 dias após o manejo das plantas de cobertura ea C/N da matéria seca das plantas no estádio de florescimento pleno, quando foram manejadas com grade.
O tempo de permanência da cobertura morta na superfície do solo, após o manejo das espécies, é determinado pela velocidade de decomposição dos resíduos culturais. Quanto mais rápida for a sua decomposição, maior a velocidade de liberação de nutrientes, porém menor é a proteção oferecida ao sol o. A velocidade de decomposição, por sua vez, está relacionada com o teor de lignina e com a relação C/ $\mathrm{N}$ dos resíduos. Quanto maiores o teor delignina ea relação $\mathrm{C} / \mathrm{N}$, mais lenta é a decomposição (Aulakh et al.,1991; Mary et al., 1996). Observa-sequea relação $\mathrm{C} / \mathrm{N}$ está intimamente ligada à proporção de aveia nos consórcios (Quadro 2) e que, à medida que aumenta a relação $\mathrm{C} / \mathrm{N}$ das plantas de cobertura, nas diferentes proporções entre gramínea eleguminosa, aumenta também a quantidade do resíduo remanescente (Figura 2).

$\mathrm{Na}$ aveia como cultura solteira $(\mathrm{C} / \mathrm{N}=33,9)$, enquanto a quantidade de resíduos remanescentes na superfície do solo após 180 dias foi de 2,63 t ha-1, eqüivalendo a 53,6\% da produção de fitomassa da espécie no momento do manejo, na ervilhaca (C/ $\mathrm{N}=13,5)$, esses valores di minuíram para, 0,53 t ha-1e 19,5\% no mesmo período, respectivamente (Quadro 1).

Esses valores são próximos daqueles obtidos por Da Ros (1993) que, 180 dias após o manejo da aveia, verificou que $57,6 \%$ dos resíduos culturais da gramínea ainda se encontravam na superfície do solo contra apenas $25 \%$ da ervil haca. O autor constatou, ainda, que, na ervilhaca, o decréscimo na quantidade de resíduos culturais ocorreu de forma exponencial, sendo mais rápido nos primeiros 30 dias, confirmando

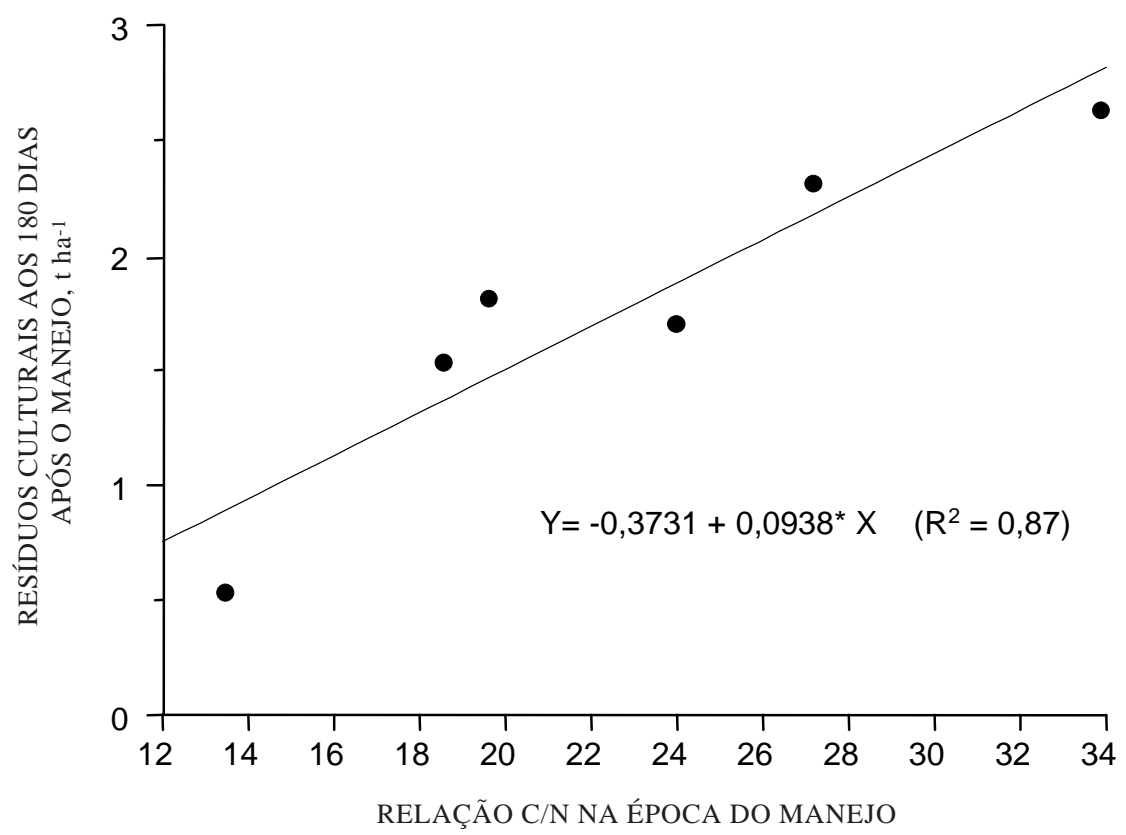

Figura 2. Relação entre a quantidade de resíduos culturais remanescentes da aveia e ervilhaca 180 dias após o manejo e a relação $\mathrm{C} / \mathrm{N}$ das espécies na época do manejo. 
a baixa persistência dos resíduos culturais ea pouca eficiência da espécie na proteção do solo após o seu manejo.

\section{Absorção de $\mathbf{N}$, produção de matéria seca e produtividade de grãos de milho}

Comparando a quantidade de $\mathrm{N}$ acumulado pelo milho nos diferentes tratamentos (Quadro 3), observa-se que, no tratamento T1, ela foi $135 \%$ superior à da aveia como cultura solteira e $85 \%$ superior à do pousio e que diminuiu à medida que aumentou a proporção da aveia nos consórcios (Quadro 2). A resposta positiva do milho na absorção de $\mathrm{N}$ em sucessão às leguminosas, em relação à aveia e ao pousio, é da mesma ordem de grandeza daquela observada por Da Ros \& Aita (1996).

A quantidade de $\mathrm{N}$ acumulado pelo milho, no estádio de pleno florescimento, em sucessão à ervilhaca pura (T1), não diferiu daquela em que foram aplicados $75 \mathrm{~kg} \mathrm{ha}^{-1}$ de $\mathrm{N}$ na forma de uréia (T7) e foi significativamente superior à dos demais tratamentos (Quadro 3). Tais resultados confirmam os de Danso \& Papastylianou (1992) e evidenciamo grande potencial das leguminosas na melhoria do balanço de $\mathrm{N}$ no solo graças à capacidade que elas mesmas apresentam de fixar o $\mathrm{N}_{2}$ atmosférico em simbiose com Rhizobium.

Quando gramíneas são utilizadas como plantas de cobertura de solo durante o inverno e a cultura econômica em sucessão for outra gramínea, como é o caso do milho, é necessária a suplementação da fertilização nitrogenada desta cultura (Sá, 1993). O não-atendimento deste requisito poderá resultar em deficiência de $\mathrm{N}$ ao milho com prejuízos na produtividade de grãos. A magnitude deste efeito será inversamente proporcional ao teor de matéria orgânica do solo que, por sua vez, irá condicionar a disponibilidade de N ao milho (Aita, 1998).

No presente trabalho, onde a disponibilidade inicial de $\mathrm{N}$ no solo é limitante à produção de grãos por cereais, o aumento da aveia no consórcio com ervilhaca, para valores acima de $10 \%$, prejudicou a produtividade do milho (Quadro 3). Observou-se que a redução chegou a 3,06 t ha-1 de grãos quando a aveia foi utilizada como cultura solteira (T6), em relação à ervilhaca solteira (T1).

Quadro 2. Coeficientes de correlação linear entre relação $C / N$, produtividade de grãos e nitrogênio acumulado pelo milho, percentagem de aveia na matéria seca total dos consórcios e resíduos culturais remanescentes

\begin{tabular}{|c|c|c|c|c|}
\hline & Produtividade grão & N Acumulado & Aveia (\%) & Resíduo remanescente \\
\hline $\mathrm{C} / \mathrm{N}$ & $-0,97 * *$ & $-0,89 *$ & $0,98 * *$ & $0,93^{* *}$ \\
\hline Produtividade grão & & $0,91^{*}$ & $-0,96 * *$ & $-0,94 * *$ \\
\hline $\mathrm{N}$ acumulado & & & $-0,84^{*}$ & $-0,93^{* *}$ \\
\hline$\%$ Aveia & & & & $0,90^{*}$ \\
\hline
\end{tabular}

**, *: Significativos a 1 e 5\%, respectivamente, pelo teste t de Student.

Quadro 3. Produção de matéria seca, quantidade de nitrogênio acumulado e produtividade de grãos de milho

\begin{tabular}{|c|c|c|c|}
\hline Tratamento & $\mathrm{N}$-acumulado & Matéria seca & Grão \\
\hline & kg ha-1 & 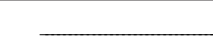 & - \\
\hline $\mathrm{T} 1-100 \% \mathrm{E}^{(2)}$ & $59,3 a^{(1)}$ & $7,49 a$ & $5,44 \mathrm{a}$ \\
\hline $\mathrm{T} 2-90 \% \mathrm{E}+10 \% \mathrm{~A}$ & $41,6 \mathrm{~b}$ & $6,15 a b$ & $4,70 a b c$ \\
\hline T3 - 75\% E + 25\% A & 36,9 bc & $5,87 \mathrm{bc}$ & $3,99 \mathrm{bcd}$ \\
\hline $\mathrm{T} 4-50 \% \mathrm{E}+50 \% \mathrm{~A}$ & $30,4 \mathrm{bc}$ & $4,86 \mathrm{bc}$ & $3,28 \mathrm{de}$ \\
\hline$T 5-25 \% E+75 \% A$ & $27,8 \mathrm{c}$ & $4,50 \mathrm{c}$ & 3,14 de \\
\hline T6 - $100 \% A$ & $25,2 \mathrm{c}$ & $4,55 \mathrm{c}$ & $2,38 \mathrm{e}$ \\
\hline T7 - Pousio $+75 \mathrm{kgha}^{-1} \mathrm{~N}$ & 55,6 a & $7,54 \mathrm{a}$ & $5,10 a b$ \\
\hline T8 - Pousio & 32,1 bc & $5,68 \mathrm{bc}$ & $3,73 \mathrm{~cd}$ \\
\hline C.V. (\%) & 14,59 & 11,60 & 13,12 \\
\hline
\end{tabular}

\footnotetext{
(1) Médias seguidas das mesmas letras, na coluna, não diferem entre si (Tukey a 5\%). ${ }^{(2)} \mathrm{E}=$ ervilhaca; $\mathrm{A}=$ aveia.
} 
A produtividade do milho no T6 (100\% A) foi aproximadamente $36 \%$ menor do que aquela obtida no tratamento em pousio sem a aplicação de N, confirmando resultados de outros trabalhos realizados em sol os com baixa disponibilidade de $\mathrm{N}$ (Aita et al., 1994; Da Ros \& Aita, 1996). Nestas condições, ocorre intensa competição pelo N disponível entre o milho e a população microbiana heterotrófica do solo, atuante na decomposição do carbono da palha da aveia, com reflexos negativos na produtividade de grãos.

Quanto ao fornecimento de $\mathrm{N}$ ao milho pelas culturas de cobertura de solo (Figura 3), calculado pela diferença entreas quantidades de $\mathrm{N}$ acumulado pela cultura nos diferentes tratamentos e no pousio, observa-seque el efoi inversamente proporcional ao aumento da aveia na mistura com ervilhaca. Assim, quando a proporção de aveia na consorciação alcançou $50 \%$ ou mais (T4, T5 eT6), omilhoacumul ou menos $\mathrm{N}$ do que no tratamento em pousio, evidenciando a predominância de imobilização de $\mathrm{N}$ do solo nestes tratamentos.

Já na ervilhaca, a partir de $75 \%$ da espécie na consorciação (T1, T2 eT3), o mil ho passou a absorver mais $\mathrm{N}$ do que no pousio, indicando aumento na disponibilidade de $\mathrm{N}$ no solo via mineralização mi crobiana do $\mathrm{N}$ da leguminosa nestes tratamentos. A diminuição no fornecimento de $\mathrm{N}$ ao milho provocada pelo aumento na proporção de aveia refletiu-se diretamente na redução da produtividade da cultura (Quadro 3).

A eficiência no $\mathrm{N}$ aplicado, estimada conforme a proposição de Mitchell \& Teel (1977), indica que a aplicação de quantidades similares de $\mathrm{N}$ (aproximadamente $75 \mathrm{~kg} \mathrm{ha}^{-1}$ de $\mathrm{N}$ via leguminosa ou uréia) resultou numa eficiência de recuperação relativamente próxima entre as duas fontes de $\mathrm{N}$, sendo de $36,4 \%$, na ervilhaca, e de $31,3 \%$, na uréia. Adicionando ao $\mathrm{N}$ da parte aérea da ervilhaca o $\mathrm{N}$ contido em seu sistema radicular $[7,1 \%$ do total acumulado pela espécie, conforme resultados de Da Ros \& Aita (1996)], a eficiência de recuperação do N aplicado pela leguminosa diminui para $33,9 \%$, aproximando-se ainda mais do $\mathrm{N}$-uréia. Estes val or es derecuperação de $\mathrm{N}$ pel o milho são inferiores aos encontrados por Aita et al. (1994) de 38\% após a ervilhaca e de $41 \%$ com a aplicação de uréia.

Tais diferenças devem estar relacionadas principalmente com as condições edafoclimáticas predominantes em cada ano agrícola. É provável que, em anos com preci pitações pluviométricas normais, a diferença entre as fontes de $\mathrm{N}$ seja menor do que em anos excessivamente chuvosos. Nesta última situação, o N da ervilhaca, por ser mais lentamente disponibilizado, pode ser mais eficientemente aproveitado pelo milho do que aquel e proveniente da uréia. Deve-sesal ientar, contudo, queo procedimento de Mitchell \& Teel (1977), adotado no presente estudo, reflete apenas a recuperação aparente do N aplicado, já que ele considera que tanto oN-ervilhaca como o N-uréia não influíram na taxa de mineralização do $\mathrm{N}$ da matéria orgânica do solo.

Os resultados deste trabal ho evidenciam que, do ponto de vista de fornecimento de $\mathrm{N}$ ao milho, para uma produtividade próxima a $5 \mathrm{t} \mathrm{ha}^{-1}$ de grãos, a demanda da cultura podeser atendida pela ervilhaca como cultura pura (T1) ou pela consorciação desta com no máximo $10 \%$ de aveia (T2).

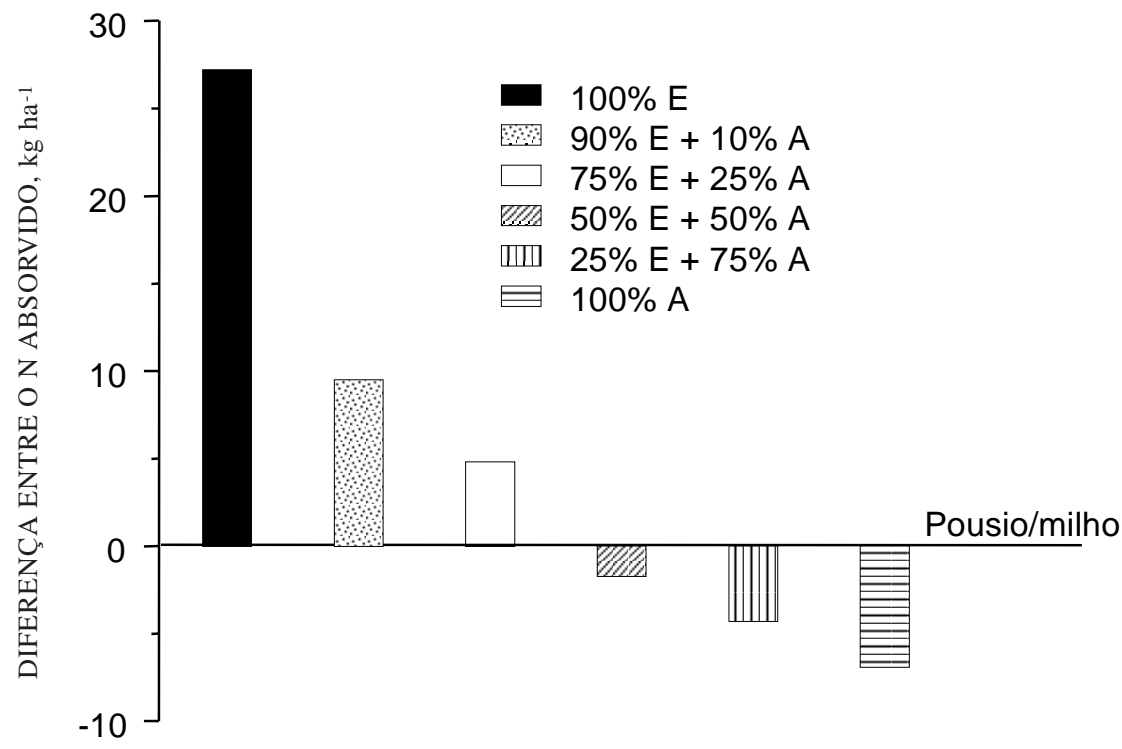

Figura 3. Fornecimento de $\mathbf{N}$ ao milho pela ervilhaca (E) e aveia (A), obtido pela diferença entre as quantidades de $\mathbf{N}$ acumulado pelo mi lho nos diferentes tratamentos e no pousio. 
Essa afirmação baseia-se no fato de que tanto a produção de matéria seca do milho como a produtividade de grãos destes dois tratamentos não diferiram daquele em que foram aplicados $75 \mathrm{~kg} \mathrm{ha}^{-1}$ de N como uréia (Quadro 3). Portanto, sob a ótica de fornecimento de $\mathrm{N}$, a recomendação usualmente utilizada de $55 \mathrm{~kg} \mathrm{ha}^{-1}$ de aveia +35 de ervilhaca (Monegat, 1991) e de 50 deaveia + 15-20 de ervilhaca (Calegari \& Peñalva, 1994) parece superestimar a proporção da aveia no consórcio, especialmente para solos com baixa disponibilidade de $\mathrm{N}$, como o do presente trabalho. Provavel mente, a recomendação destes autores seja mais adequada para solos ricos em matéria orgânica, ondea imobilização microbiana do $\mathrm{N}$ do solo, provocada pela aveia, tenha reflexos menos negativos sobre o milho.

Apesar de o aumento na proporção da ervilhaca ter favorecido o suprimento de $\mathrm{N}$ ao milho, este provocou diminuição no tempo de permanência dos resíduos culturais na superfície do solo, deixando-o mais desprotegido. Assim, se a prioridade for o fornecimento de $\mathrm{N}$ ao milho, a escolha deve recair sobre aqueles consórcios com predominância de ervilhaca. Por outrolado, se o objetivo principal for a proteção do solo, o aumento na proporção de aveia no consórcio deve ser a estratégia escol hida. Neste último caso, haverá necessidade de suplementação de $\mathrm{N}$ ao mil ho via adubação mineral, cuja dose será tanto mais el evada quanto maior for a proporção de aveia no consórcio. O estabel ecimento de doses de $\mathrm{N}$ mineral por aplicar, considerando a proporção de aveia e ervilhaca consorciadas, visando conjugar fornecimento de $\mathrm{N}$ e rendimento do milho com persistência dos resíduos culturais na superfície do solo, é um aspecto que deverá ser investigado em futuros estudos.

\section{CONCLUSÕES}

1. Aumentando a participação da gramínea na consorciação de aveia + ervilhaca, utilizadas como culturas de cobertura no inverno, houve um incremento na relação $\mathrm{C} / \mathrm{N}$ da fitomassa e um aumento na persistência dos resíduos culturais sobre a superfície do solo, causando decréscimo no fornecimento de $\mathrm{N}$ e na produtividade degrãos para a cultura do milho em sucessão.

2. A consorciação que proporciona maior produtividade de milho para Argissolos distróficos do Rio Grande do Sul, equivalente ao obtido em sucessão à ervil haca como cultura solteira eao pousio com $75 \mathrm{~kg} \mathrm{ha}^{-1}$ de N-uréia, foi estabel ecida com $90 \%$ de sementes de ervilhaca ( $72 \mathrm{~kg} \mathrm{ha}^{-1}$ ) e $10 \%$ de aveia $\left(8 \mathrm{~kg} \mathrm{ha}^{-1}\right)$.

\section{LITE RATURA CITADA}

AITA, C. Dinâmica do nitrogênio no sol o durantea decomposição de plantas de cobertura: efeito sobre a disponibilidade de nitrogênio para a cultura em sucessão. In: FRIES, M.R. \& DALMOLIN, R.S.D., eds. Curso de atualização em recomendação de adubação e calagem: ênfase em plantio direto. Santa Maria, Universidade Federal deSanta Maria, 1998. p.76-111.

AITA, C.; CERETTA, C.A.; THOMAS, A.L.; PAVINATO, A. \& BAYER, C. Espécies de inverno como fonte de nitrogênio para o milho no sistema de cultivo mínimo e feijão em plantio direto. R. Bras. Ci. Solo, 18:101-108, 1994.

AULAKH, M.S.; DORAN, J .W.; WALTERS, D.T.; MOSIER, A.R. $\&$ FRANCIS, D.D. Crop residuetype and placement effects on denitrification and mineralization. Soil Sci. Soc. Am. J ., 55:1020-1025, 1991

BALDANI, V.L.; BALDANI, J .I \& \& DÖBEREINER, J . I noculation of field-grown wheat (Triticum aestivum) with Azospirillum spp. in Brazil. Biol. Fertil. Soils, 4:37-40, 1987.

BODDEY, R.M. \& DÖBEREI NER, J . Nitrogen fixation associated with grasses and cereals: Recent results and perspectives for future research. Plant Soil, 108:53-65, 1988.

BRAGAGNOLO, N. \& MIELNICZUK, J . Cobertura do solo por resíduos de oito seqüências de culturas e seu relacionamento com a temperatura e umidade do solo. $R$. Bras. Ci. Solo, 13:91-98, 1990.

CABALLERO, R.; GOICOECHEA, E.L. \& HERNAIZ, P.J . Forage yields and quality of common vetch and oat sown at varying seeding ratios and seeding rates of vetch. Field Crops Res., 41:135-140, 1995.

CALEGARI, A.; MONDARDO, A.; BULISANI, E.A.; WILDNER, L.P.; COSTA, M.B.B.; ALCÂNTARA, P.B.; MIYASAKA, S. \& AMADO, T.J .C. Adubação verde no sul do Brasil. 2.ed. Rio de J aneiro, Assessoria e Serviços e Projetos em Agricultura Alternativa AS-PTA, 1993. 346p.

CALEGARI, A. \& PEÑALVA, M. Abonos verdes: Importancia agroecológica y especies com potencial de uso en el Uruguay. Canelones, MGAP (J UNAGRA)-GTZ, 1994. 151p.

DA ROS, C.O. Plantas de inverno para cobertura do solo e fornecimento de nitrogênio ao milho em plantio direto. Santa Maria, Universidade Federal de Santa Maria, 1993. 85p. (Tese de Mestrado)

DA ROS, C.O. \& AITA, C. Efeito de espécies de inverno na cobertura do solo e fornecimento de nitrogênio ao milho em plantio direto. R. Bras. Ci. Solo, 20:135-140, 1996.

DANSO, S.K.A.\& PAPASTYLIANOU, I. Evaluation of the nitrogen contribution of legumes to subsequent cereals. J . Agric. Sci., 119:13-18, 1992.

DEBARBA, L. \& AMADO, T.J.C. Desenvolvimento de sistemas de produção de milho no sul do Brasil com características de sustentabilidade. R. Bras. Ci. Solo, 21:473-480, 1997.

DERPSCH, R. \& CALEGARI, A. Guia de plantas para adubação verde de inverno. Londrina, Instituto Agronômico do Paraná, 1985. 96p. (Documentos I APAR, 9) 
DERPSCH, R.; SIDIRAS, N. \& HEINZMANN, F.X. Manejo do sol o com coberturas verdes de inverno. Pesq. Agropec. Bras., 20:761-773, 1985.

ELGERSMA, A. \& HASSINK, J . Effects of white clover (Trifol ium repens $L$.) on plant and soil nitrogen and soil organic matter in mixtures with perennial ryegrass (Lolium perenne L.). Plant Soil, 197:177-186, 1997.

GOODMAN, P.J. Nitrogen fixation, transfer and turnover in upland and lowland grass-clover swards, using ${ }^{15} \mathrm{~N}$ isotope dilution. Plant Soil, 112:247-254, 1988.

MARY, B.; RECOUS, S.; DARWIS, D. \& ROBIN, D. Interactions between decomposition of plant residues and nitrogen cycling in soil. Plant Soil, 181:71-82, 1996.

MCNEIL, A.M. \& WOOD, M. ${ }^{15} \mathrm{~N}$ estimates of nitrogen fixation by white clover (Trifolium repens L.) growing in a mixture with ryegrass (Lolium perenne L.). Plant Soil, 128:265-273, 1990.

MITCHELL, W.H. \& TEEL, M.R. Winter-anual cover crops for no-tillage corn production. Agron. J ., 69:569-573, 1977.

MONEGAT, C. Plantas de cobertura do solo: Características e manejo em pequenas propriedades. Chapecó, Edição do Autor, 1991. 337p.

OUKNIDER, M.; J ACQUARD, P. \& ELKHYARI, D. Concurrence chez Vicia sativa $L$. et Avena sativa L. II. Effets des contraintes hydriques et nutritionnelles sur la biomasse et la distribution des resources. Agronomie, 11:821-828, 1991.
PAVINATO, A.; AITA, C.; CERETTA, C.A. \& BEVILÁQUA, G.P. Resíduos culturais de espécies de inverno e o rendimento de grãos de milho no sistema de cultivo mínimo. Pesq. Agropec. Bras., 29:1427-1432, 1994.

SÁ, J .C.M. Manejo da fertilidade do solo no sistema de plantio direto. In: EMPRESA BRASILEIRA DE PESQUISA AGROPECUÁRIA. Centro Nacional de Pesquisa do Trigo. EMBRAPA/CNPT. Plantio direto no Brasil. Passo Fundo, 1993. p.37-60.

SIQUEIRA, O.J.F.; SCHERER, E.E.; TASSINARI, G.; ANGHINONI, I.; PATELLA,J .F.;TEDESCO, M.J .; MILAN, P.A . \& ERNANI, P.R. Recomendações de adubação e calagem para os estados do Rio Grande do Sul e Santa Catarina. Passo Fundo, Centro Nacional de Pesquisa de Trigo, 1987. 100p.

SIQUEIRA, J.O. \& FRANCO, A.A. Biotecnologia do solo: fundamentos e perspectivas. Brasília, Ministério da Educação e Cultura, 1988. 236p.

TEDESCO, M.J .; WOLKWEISS, S.J . \& BOHNEN, H. Análises de solo, plantas e outros materiais. Porto Alegre, Universidade Federal do Rio Grande do Sul, 1985. 118p. (Boletim Técnico, 5)

WILDNER, L.P. \& DADALTO, G.G. Adubos verdes de inverno para o oeste catarinense. R. Agropec. Catarinense, 5:3-6, 1992. 